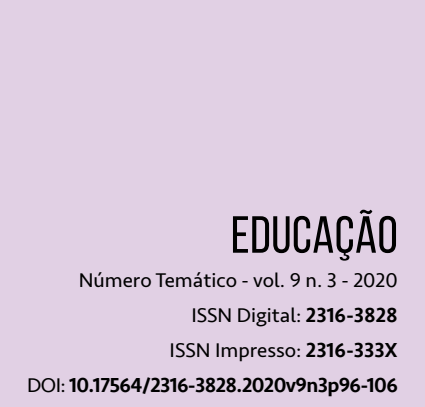

\section{REFLEXÃO SOBRE A INTENCIONALIDADE EMANCIPATÓRIA DAS PRÁTICAS DA EDUCAÇ̃̃O NÃO-ESCOLAR: A ÓTICA DE UMA ASSOCIAÇÃO}

\section{REFLECTION ON THE EMANCPATORY INTENTIONALITY OF NON-SCHOOL EDUCATION PRACTICES: THE OPTICS OF AN ASSOCIATION}

\section{REFLEXIÓN SOBRE LA INTENGIONALLDAD EMANCIPATORIA DE LAS PRÁCTICAS DE LA EDUCACIÓN NO-ESCOLAR: LA ÓPTICA DE UNA ASOCIACIÓN}

Patrícia Modesto da Silva ${ }^{1}$ Sérgio Haddad ${ }^{2}$

\section{NÚMERO TEMÁTICO}

\section{RESUMO}

0 presente trabalho é um recorte da dissertação 0 impacto das práticas de educação não-escolar na vida de crianças e adolescentes em situação de vulnerabilidade social: estudo de caso de uma associaçãa $o^{3}$. Nele se busca problematizar a ambiguidade entre o discurso e a práxis da Associação pesquisada em relação a seu público-alvo, no que diz respeito à educação não-escolar como cenário de prática de uma educação libertadora (FREIRE, 1967). A partir de diário de campo, entrevista em profundidade, rodas de conversa e análise de discurso, busca-se analisar, nas falas dos sujeitos (funcionários, crianças/adolescentes atendidos e seus familiares) o discurso, a intencionalidade e a prática que se efetiva, amparando a fundamentação teórica em autores como Freire $(1959,1967,1979)$, Canário (2006), Afonso (2001), Brandão (1995), Castel (2005) e Bauman (2013), buscando problematizar os resultados obtidos na referida dissertação, que mostraram o papel da educação não-escolar na direção de uma educação emancipatória.

\section{PALAVRAS-CHAVE}

Práticas Educativas. Educação Não-escolar. Emancipação.

3 Dissertação orientada pelo co-autor. 


\section{RESUMEN}

Este documento es un recorte de la disertación El impacto de las prácticas educativas no escolares en la vida de niños y adolescentes socialmente vulnerables: estudio de caso de una Asociación busca problematizar la ambigüedad entre el discurso y la praxis de la Asociación investigada en relación con su público objetivo, con respecto a la educación no escolar como un escenario para la práctica de una educación liberadora (FREIRE, 1967). A partir de un diario de campo, entrevistas en profundidad, ruedas de conversación y análisis del discurso, buscamos analizar, en los discursos de los sujetos (empleados, niños/adolescentes asistidos y sus familiares) el discurso, la intencionalidad y la práctica que tiene lugar, apoyando la base teórica en autores como Freire $(1959,1967,1979)$, Canário (2006), Afonso (2001), Brandão (1995), Castel (2005) y Bauman (2013) y buscando problematizar los resultados obtenidos en esta disertación, que mostró el papel de la educación no escolar hacia una educación emancipadora.

\section{PALABRAS CLAVE}

Prácticas educativas. Educación no escolar. Emancipación.

\section{ABSTRACT}

This paper is a clipping of the dissertation The impact of non-school education practices on the lives of socially vulnerable children and teenagers: a case study of an association. It seeks to problematize the ambiguity between the discourse and the praxis of the researched Association in relation to its target audience, regarding non-school education as a setting for the practice of liberating education (FREI$R E$, 1967). From a field diary, in-depth interview, conversation circles and discourse analysis, we seek to analyze, in the speeches of the subjects (employees, children / teenagers assisted and their family members) the discourse, intentionality and practice that takes place, supporting the theoretical foundation in authors such as Freire (1959, 1967, 1979), Canário (2006), Afonso (2001), Brandão (1995), Castel (2005) and Bauman (2013) and seeking to problematize the results obtained in this dissertation, which showed the role of non-school education in the direction of an emancipatory education.

\section{KEYWORDS}

Educational Practices Non-School Education. Emancipation 


\section{INTRODUÇ̧̃̃o}

A vulnerabilidade social vivida por crianças e adolescentes da periferia da zona norte de Caxias do Sul, no estado do Rio Grande do Sul, não é diferente de outras do restante do País, como acompanhamos por meio de notícias, estatísticas e estudos. Uma associação que atende crianças e adolescentes, no contraturno escolar, nessa localidade, foi o cenário para a pesquisa de dissertação que teve como tema "As práticas da educação não-escolar, como contributo para o desenvolvimento do sujeito, criando possibilidades de uma vida digna” (SILVA, 2018).

O objetivo geral era analisar como as práticas de educação não-escolar podem impactar a vida de crianças e adolescentes em situação de vulnerabilidade social. No estudo, propôs-se uma reflexão sobre a intencionalidade emancipatória das práticas da educação não-escolar na ótica da associação ${ }^{4}$ estudada. 0 recorte, portanto, buscou analisar as práticas educativas a partir do olhar dos profissionais da instituição. Sustentamos este conceito - intencionalidade emancipatória com base no que Freire (2003, p. 172) define sobre o que as práticas desalienadoras devem buscar: “[...] um máximo de consciência crítica com que as classes populares se entregassem ao esforço de transformação da sociedade brasileira".

O percurso metodológico utilizado para a construção do corpus empírico foi a análise documental; a entrevista em profundidade, semiestruturada; rodas de conversa e diário de campo, caracterizando como método-base a etnografia. A partir das informações que emergiram do campo, a análise do discurso foi o caminho para a percepção, assimilação e interpretação das informações.

A análise do discurso produzido nas entrevistas em profundidade e nas rodas de conversa com os funcionários da instituição levou a algumas inferências importantes como: 1. A inquietude da Associação em oportunizar vivências distintas das experienciadas na escola, na família e na comunidade; 2. Em alguns momentos, a associação revelou juízo de valor sobre comportamentos vindos das famílias e de vivências externas dos adolescentes; 3. 0 espaço da Organização Não Governamental (ONG) foi apresentado como lugar seguro, de aquisição de valores e reflexão sobre a educação como ferramenta para a emancipação dos sujeitos; 4. Os profissionais verbalizaram a necessidade de estreitar vínculo com as famílias e escolas, descrevendo alguns dos esforços para isso; 5. A instituição sinalizou certa dependência das famílias que recorriam a ela para a resolução de seus problemas, na contramão de uma educação libertadora; 6 . Declararam buscar a socialização, a emancipação, a cidadania e a criticidade, provocando experiências e aprendizagens que priorizassem o respeito a si e ao outro.

A oportunidade de conhecer os objetivos e processos de funcionamento da associação ganhou conotação especial nas vozes dos sujeitos, aqui definidos como profissionais ouvidos. Uma questão bastante relevante foi o caminho percorrido entre a intenção (discurso), a prática e os resultados.

4 As associações emergiram, entre outros objetivos, com o propósito de atender necessidades relacionadas às áreas da saúde, do meio ambiente e da sociedade, preocupando-se com questões de gênero, raça e cor, entre outras. 0 estudo se limita a uma entidade que trabalha com crianças e adolescentes, caracterizada como "serviços de convivência e fortalecimento de vínculos", conforme Lei Orgânica da Assistência Social, n 8.742, de 07 de dezembro de 1993 e a Resolução nº 109, de 11 de dezembro de 2009. 
Acrescentam-se a esse trajeto dois olhares: um interno - como os colaboradores entendem o trabalho desenvolvido e, outro externo - a percepção dos demais sujeitos do corpo social (a exemplo da comunidade). Algumas falas de profissionais evidenciaram que os múltiplos públicos ${ }^{5}$ que acessam a instituição, por vezes, não compreendem seus propósitos, que está, sobretudo, na educação não-escolar, aqui entendida segundo Canário (2006, p. 37) como:

A maior parte das situações de aprendizagem são, por outro lado, não formais (não obedecendo aos requisitos do modelo escolar) e sequer são deliberadas, ou seja, não há consciência de que o principal objetivo seja aprender algo. A aprendizagem surge como co-produto de uma ação. É nesse ponto de vista que, cada vez mais, estou convencido de que a educação não formal, ou seja, a educação não-escolar, deverá se constituir como o ponto de referência para pensar a educação escolar.

Em consonância com o autor, o objetivo deste artigo, é, portanto, a análise de práticas educativas, a partir do olhar dos profissionais da instituição selecionada.

Inicialmente, traçamos três propósitos neste estudo: 1. Compreender e refletir sobre a forma como é feito o levantamento de necessidades do público atendido, para dar sequência ao planejamento de ações; 2. Analisar como os funcionários veem o serviço/atendimento que prestam às crianças e adolescentes; 3 . Estudar, refletindo sobre os resultados das práticas educativas apontados pela instituição.

\section{CAMINHOS E DESCAMINHOS PARA A EDUCAÇÃO}

Parece evidente uma relação entre educação bancária ${ }^{6}$ e a perpetuação da desigualdade e da exclusão social, Bauman (2013) e Castel (2005), nos auxiliam a analisar essa questão. Não é somente o capital que define a condição de vida dos sujeitos, mas a garantia de direitos mínimos para a sobrevivência digna. Conforme Castel (2005), a desigualdade social é resultado da bagagem histórica, da má atuação de um Estado de direito e do avanço acelerado do mercado financeiro. Assim, segundo o autor, uma mudança social eficaz passaria por transformações estruturais que atendessem necessidades prioritárias e criasse possiblidades de futuro. A educação com vistas à emancipação poderá ser parte da alternativa para a inclusão social, mobilização social e empoderamento dos sujeitos.

Freire (1967, p. 36) vê a educação como: “[...] algo de absolutamente fundamental entre nós”. Para ele, desvestida da roupagem alienada e alienante, a educação é uma força de mudança e de libertação. Ela deveria ser a oportunidade de o sujeito ler o mundo e entender seu papel como cidadão e protagonista de sua história. No entanto, os indivíduos não podem esperar do Estado enfraquecido

5 Com a expressão múltiplos públicos queremos definir: familiares, escolas do entorno da associação, voluntários, mantenedores, apoiadores e comunidade local.

6 Conforme Freire (1987, p. 58) “Em lugar de comunicar-se, o educador faz "comunicados” e depósitos que os educandos, meras incidências, recebem pacientemente, memorizam e repetem. Eis aí a concepção "bancária” da educação, em que a única margem de ação que se oferece aos educandos é a de receberem os depósitos, guardá-los e arquivá-los.” 
perante o mercado financeiro e omisso de seu papel, uma solução que não sejam medidas paliativas. O Estado apresenta-se como regulador, fiscalizador, propagador de políticas públicas, sem o objetivo de buscar a garantia da equidade num processo de desenvolvimento equilibrado e justo.

A ingenuidade dos sujeitos os aprisiona cada vez mais, deixando-os à margem de uma sociedade capitalista e egocêntrica. Ao apresentar a visão da educação bancária, Freire (1987, p. 60) esclarece que esta prática estimula a "[...] ingenuidade e não sua criticidade, satisfaz aos interesses dos opressores: para estes, o fundamental não é o desnudamento do mundo, a sua transformação". Concepção que vai em sentido contrários para a libertação dos sujeitos com vistas a desenvolver uma consciência crítica para contribuir para com a mudança social.

Para Brandão (1995, p. 78):

A idéia de que a educação não serve apenas à sociedade, ou à pessoa na sociedade, mas à mudança social e à formação consequente de sujeitos e agentes na/da mudança social, pode não estar escrita de maneira direta nas “leis do ensino". Afinal, as leis quase sempre são escritas por quem pensa que nem elas e nem o mundo vão mudar um dia.

Corroboramos com o autor que a educação pode ser um caminho para a emancipação dos sujeitos e das massas, ou, pode ser um caminho alienante, manipulador e opressor. Acreditar numa mudança social é essencial para que haja transformação, tanto quanto confiar na educação e nos sujeitos como protagonistas para tal transição. Conforme Freire (2000, p. 67): “Se a educação sozinha não transforma a sociedade, sem ela tampouco a sociedade muda".

A partir de nossa imersão no campo, ficaram evidentes as dificuldades enfrentadas por quem mora na área estudada: insegurança, falta de acesso a direitos básicos, violência, drogas, trabalho infantil e prostituição, informações também colhidas nos relatos dos profissionais da instituição.

Segundo (SILVA, 2018, p. 39), a associação pesquisada foi criada em 1995, e inicialmente atendia as famílias do bairro Fátima Baixo, no salão paroquial, fazendo encaminhamento para emprego, reuniões de conscientização alimentar e saúde e distribuição de alimentos e roupas. Até 1998, quando a prefeitura cedeu um terreno, onde se mantém até hoje, focou seus objetivos no atendimento de crianças e adolescentes em situação de vulnerabilidade social, realidade da comunidade em que está inserida.

Ainda, segundo a autora, com o intuito de intensificar e qualificar a assistência, a partir de 2016, a instituição focou seu atendimento com crianças e adolescentes, de 06 a 15 anos, no contraturno escolar, nos turnos da manhã e tarde, durante o ano todo. Em 2017, com o propósito de oferecer Serviços de Convivência e Fortalecimento de Vínculos, atendia cerca de 230 crianças e adolescentes fornecendo alimentação (café da manhã, almoço e pré-janta); acolhimento; atividades: desportivas, arte e literárias; oficinas: circo, teatro, música, dança; telecentro e culinária.

A programação proposta está alinhada com os projetos: Construindo Valores, Educação Ambiental, Literário, Educação para a Vida e Arte e Cultura, planejadas e debatidas nas reuniões pedagógicas mensais. 0 suporte financeiro para atender essa estrutura é mantido por meio de convênios públicos, com eventos, venda de produtos, doações espontâneas de pessoas físicas e jurídicas e o apadrinhamento. 
Frente aos desafios colocados, estratégias foram desenvolvidas voltadas para seu público prioritário. Conforme relato dos educadores sociais (04/10/2017), a recepção diária deve ser acolhedora, 0 que permite perceber em que condições as crianças e os adolescentes chegam:

[...] uma coisa que a gente achou bastante forte né, o acolhimento e o vínculo. Então todos os dias eles são acolhidos aqui pelos educadores, lá no pátio e a gente vai acolhendo eles lá... Eles já chegando contando tudo, tu está lá pronta para ouvir, né, então eles chegam lá, nós recebemos, ouvimos, recebemos eles, damos aquele abraço, aquele beijo, a gente recebe uma flor, a gente recebe uma bala, o carinho deles, as novidades, então esse acoIhimento faz a diferença, então eles sabem que abriu o portão o educador dele vai tá lá, se não tá tem um outro.

A preocupação e o respeito com os usuários estão presentes no cotidiano da instituição, o que mostra o olhar direcionado para a emancipação dos sujeitos. As atividades devem ser voltadas, segundo os profissionais, à emancipação e ao protagonismo dos sujeitos, pois entendem que a criança e adolescente precisam se responsabilizar por sua higiene, alimentação, estudos e por vezes segurança, quando estão fora dos muros da instituição.

Afonso (2001, p. 35) aponta a importância da educação não-escolar, que reconhece como informal e não formal:

[...] diferentes racionalidades políticas e pedagógicas, exigindo por isso, dos educadores e investigadores socialmente comprometidos, uma vigilância epistemológica redobrada, para que aqueles que a esse campo referenciam as suas práticas e reflexões possam ajudar a construí-lo como lugar de referência de uma educação crítica e emancipatória...

A educação, aqui entendida como o ato de aprender com o outro e com o meio, deve servir de suporte para a conscientização do espaço em que vivem, dos perigos que suas escolhas podem representar e torná-los críticos e seguros. Consoante com o que Brandão (1995, p. 78) apresenta: "A educação do homem existe por toda a parte e, muito mais do que a escola, é o resultado da ação de todo o meio sociocultural sobre os seus participantes. É o exercício de viver e conviver o que educa”.

A globalização, os avanços tecnológicos e a acumulação de capital e poder marcam a forma de vida e explicitam a dicotomia na função do Estado. A realidade da política que perdeu sua finalidade, entre atender a necessidades dos cidadãos e a interesses mercadológicos e individuais, contribui para a ampliação da desigualdade e da exclusão social e uma educação alienante Brandão (1995), que, segundo Castel (2005, p. 58), promove o deslocamento do “Estado social” para um “Estado secundário”, que se faz valer pelo exercício da autoridade.

Assim, as pessoas buscam seus caminhos de forma individual, para o bem-estar e segurança, o que torna a sociedade individualista e enfraquecida na busca de seus direitos. Com base em Castel (2005, p. 59), com o “[...] o enfraquecimento do estado nacional-social, indivíduos e grupos sofrem”. Esse cenário apresenta como desfecho uma educação bancária e conformista, que humilha, degrada e exclui. Com o mercado livre para sua atuação financeira desmedida, o Estado reforça seu papel baseado em promes- 
sas. A impossibilidade de o sujeito fazer parte do mercado torna-o excluído e classificado como um peso para a sociedade, pois o Estado se exime de seu papel. Bauman (2013, p. 38) afirma:

\begin{abstract}
Suspeito que os prováveis veículos para conduzir a esse "planeta social” não sejam Estados territorialmente soberanos, e sim organizações e associações não governamentais cosmopolitas, aquelas que atingem diretamente as pessoas necessitadas por sobre as cabeças dos governos locais "soberanos" e sem interferência deles.
\end{abstract}

Diante dessa realidade, a associação apresenta às crianças e adolescentes uma perspectiva como caminho para sua emancipação e libertação: formar cidadãos autônomos. Embora não substitua a atuação do Estado, as ONG podem ser importantes agentes de transformação em diferentes setores da sociedade: seja como um meio de reivindicação, de representatividade, na implementação de políticas públicas, ainda, para a conscientização do papel social e político de indivíduos.

Neste estudo, foram exploradas as percepções dos educadores sociais, da pedagoga, das assistentes sociais e de adolescentes captadas em rodas de conversa, entrevistas e registros do diário de campo. Esse material, juntamente com a fundamentação teórica, serviu como arcabouço para a análise do discurso dos entrevistados, levando às seguintes considerações.

O planejamento das práticas da associação considera as entrevistas com crianças, adolescentes e famílias (pesquisa de opinião, semestral) para o planejamento e elaboração das práticas. Esse recurso, objetiva conhecer as famílias, compreender as dificuldades com a aproximação do público, valorizar suas opiniões e inteirar-se dos interesses e expectativas quanto ao trabalho que será desenvolvido. Emergem, além de dificuldades com relação à aprendizagem, particularidades da vida dos atendidos que são consideradas nas oficinas ministradas.

A instituição compreende não ter "pernas" nem ser seu papel percorrer o caminho com eles, mas, sim, prepará-los para a vida. Desta forma, pensam em oficinas, projetos e parcerias que visam ao desenvolvimento intelectual, social e humano dos sujeitos. Os educadores sociais, assistentes sociais e a pedagoga compreendem que essas crianças e adolescentes precisam de afeto, de carinho, de atenção e ainda mais, de formação direcionada ao protagonismo e a construção de seu futuro.

Algumas das práticas são pensadas, visando a aproximação e o estreitamento de laços com o público alvo, os alunos. 0 objetivo é que as crianças e adolescentes busquem na instituição apoio para a resolução de problemas e oportunidade, por meio de diálogo, para defenderem seus interesses. Conforme corrobora Freire (1979, p. 28):

0 trabalhador social que opta pela mudança não teme a liberdade, não prescreve, não manipula, não foge da comunicação, pelo contrário, a procura e vive. Todo seu esforço, de caráter humanista, centraliza-se no sentido da desmistificação do mundo, da desmistificação da realidade.

A visão dos educadores sociais quanto ao trabalho realizado se mostrou ambígua em algumas oportunidades. Talvez porque esta indecisão esteja entre o acolhimento/protecionismo e o acolhi- 
mento/emancipação, mostrando que alguns discursos não condiziam com a prática, por apresentarem um sentimento de proteção forte quanto à questão do amparo dos adolescentes em relação à comunidade e, por vezes, até de algumas famílias.

Assim como mostra a fala da assistente social (04/10/2017), quando se refere à violência e negligência familiar: "não reprodução de alguns comportamentos que vêm da família, que vêm da comunidade...", distanciando-se das condições concretas de existência das famílias atendidas. Nos discursos, no entanto, estava presente a preocupação quanto ao planejamento de atividades e vivências que seriam experenciadas pelos adolescentes, as quais objetivavam a emancipação, participação e empoderamento ${ }^{7}$ dos sujeitos - direcionamentos em consonância com o conceito de educação libertadora de Freire (1959, p. 9): “[...] a organicidade do processo educativo implica na sua integração nas condições do tempo e do espaço a que se aplica para que possa alterar ou mudar essas mesmas condições”.

Apresentaram-se como sendo seu dever direcionar as escolhas de futuro: como concluir os estudos, ter maturidade para constituir família, buscar uma profissão "reconhecida”, desviar de drogas, prostituição e violência, sem, no entanto, confrontar com a realidade encontrada e sem mostrar e discutir os caminhos para chegar a elas, ampliando a consciência dos educandos. 0 campo mostrou, entre outros aspectos, dissonância entre práxis e discurso. Percebeu-se o envolvimento emocional da equipe com o público o que, nitidamente, tolhe decisões importantes.

Esse cenário acaba por desenhar e reproduzir uma situação paternal de dependência tanto de crianças e adolescentes quanto das famílias. Não utilizam qualquer processo avaliativo das crianças e adolescentes, e não há qualquer pesquisa sobre os egressos, o que poderia oferecer feedback sobre o cumprimento dos objetivos da instituição. Os profissionais procuram o protagonismo e à emancipação no planejamento, mas por vezes sua aplicabilidade não parece dar conta de atingi-los justamente pela preocupação que apresentam em proteger as crianças e adolescentes de suas realidades.

Conforme Brandão (1995, p. 12): “[...] a mesma educação que ensina pode deseducar, e pode correr o risco de fazer ao contrário do que pensa que se faz, ou do que inventa que pode fazer...”. Talvez porque a questão esteja na ambiguidade entre o acolhimento/protecionismo e o acolhimento/emancipação. Ao analisarmos as falas e experiências fica evidente a intencionalidade emancipatória no planejamento das práticas, mas percebe-se que nem sempre ela está presente na relação ambígua entre a escola e a instituição, ou entre o papel da família e o da instituição. As práticas precisam incentivar a autonomia e a independência levando em conta o que Freire (2003, p. 151) define como:

[...] assistência e não assistencialismo, de tal maneira que a assistência se possa converter num estímulo ou num desafio capaz de transformar o "assistido" de hoje no sujeito que, tomando o amanhã sua história na mão a refaz plena de justiça, de decência e de boniteza, é um ato de sabedoria e de esperança.

O autor ainda ressalta a relevância de respeitar o conhecimento e a "identidade cultural dos educandos” bem como considerar as dificuldades vividas na realidade de onde vem. Além disso,

7 Conceitos importantes como "[...] propósito de desenvolver uma consciência crítica, criando um senso de capacidade e responsabilidade moral no indivíduo para mudar sua vida e o mundo em torno de si.” Freire (2003, p. 183) 
reforça sobre a postura do docente, que precisa ser carinhosa, acolhedora, mas ter clareza política, ter competência científica, dentre outros atributos para se chegar ao objetivo estabelecido. A intencionalidade e a pré-disposição dos profissionais parecem estar no caminho, mas será fundamental fluir na mesma direção de suas práticas.

\section{CONSIDERAÇÕES FINAIS}

A relevância desta análise está na discussão sobre a importância da educação não-escolar como caminho para a emancipação e autonomia dos sujeitos, em consonância com Freire (1959). A conscientização e libertação dos sujeitos por meio da educação - estabelecida na interação com o outro e o meio em que vive, traz oportunidades de mudar sua visão de mundo, antes focada em seu território, agora ampliada. A consciência crítica da sua realidade é fundamental para que se possa buscar direitos e conquistar espaços. O formato que se defende, de uma educação libertadora, está na contramão do paternalismo, da não validação de conhecimentos prévios dos alunos e da legitimação do contexto social onde vivem.

A associação mostrou ambiguidade a esse respeito, uma discrepância entre discurso e prática. Embora tenha como meta a emancipação e protagonismo dos sujeitos, o sentimento assistencial e protetor em alguns momentos apresenta-se como obstáculo. 0 juízo de valor da instituição em relação às condutas vindas das famílias e de vivências externas das crianças e adolescentes, o que ficou notório na trajetória da pesquisa, demostram tais comportamentos assistencialistas.

A partir de nossa imersão no campo ficou notório que a associação dispunha de boas intenções ao realizar sua função. Apresentou-se como um lugar seguro e acolhedor. Espaço que demonstrou preocupação em apoiar e orientar caminhos com a intenção de formar "cidadãos de bem" e com condições de fazer suas próprias escolhas. No entanto, inferiu-se que as práticas precisam ser alinhadas com o discurso.

Talvez sejam necessários formação profissional e atendimento psicológico, visando a amenizar o desgaste que sofrem ao trabalhar com essa realidade que traz consigo os problemas de violência, de tráfico de drogas, de prostituição, das ocupações irregulares, do trabalho infantil e da carência de oportunidades profissionais da comunidade para o interior da instituição. Mas que não se perca a vontade de mudar o cenário e, principalmente, o espírito obstinado em fazer alguma diferença para a libertação e consciência de cidadãos.

\section{REFERÊNCIAS}

AFONSO, Almerindo Janela. Os lugares da educação. In: SIMSON, Olga Rodrigues Von; PARK, Margareth Brandini; FERNANDES, Renata Sieiro (Org.). Educação não-formal: cenários da criação. Campinas: Unicamp/Centro de Memória, 2001. 
BAUMAN, Zygmunt. Danos colaterais. Desigualdades sociais numa era global. Rio de Janeiro: Jorge Zahar Ed., 2013.

BRANDÃO, Carlos Rodrigues. 0 que é educação. São Paulo: Brasiliense, 1995.

CANÁRIO, Rui. A escola tem futuro? Das promessas às incertezas. Porto Alegre: Artmed, 2006.

CASTEL, Robert. A insegurança social o que é ser protegido? Petrópolis-RJ: Vozes, 2005.

FREIRE, Paulo. Educação como prática da liberdade. 24. ed. Rio de Janeiro: Paz e Terra Ltda, 1967.

FREIRE, Paulo. Educação e Mudança. 12. ed. Rio de Janeiro: Paz e Terra, 1979

FREIRE, Paulo. Educação e atualidade brasileira. 1959. Tese de Concurso para a Cadeira de História e Educação - Escola de Belas Artes de Pernambuco, Recife-PE, 1995. Disponível em: http://www. acervo.paulofreire.org:8080/jspui/handle/7891/1976. Acesso em: 19 abr. 2019.

FREIRE, Paulo. Cartas a Cristina. Reflexões sobre minha vida e minha práxis. 2. ed. São Paulo: Editora UNESP, 2003.

FREIRE, Paulo. Pedagogia do oprimido. 17. ed. Rio de Janeiro: Paz e Terra, 1987.

FREIRE, Paulo. Pedagogia da indignação: cartas pedagógicas e outros escritos. Apresentação de Ana Maria Araújo Freire. Carta-prefácio de Balduino A. Andreola. São Paulo: Editora UNESP, 2000

SILVA, Patrícia Modesto da. 0 impacto das práticas de educação não-escolar na vida de crianças e adolescentes em situação de vulnerabilidade social: estudo de caso de uma associação. 2018. Dissertação (Mestrado em Educação) - Universidade de Caxias do Sul, Caxias do Sul-RS, 2018. 
1 Mestre em Educação (2018) pela Universidade de Caxias do Sul; Doutoranda no Programa de Pós-Graduação em Diversidade Cultural e Inclusão Social - FEEVALE; Graduada em Pedagogia - Licenciatura (2008) pela Universidade do Vale do Rio dos Sinos. E-mail: sergiohaddad@ucs.br

2 Doutor em história e filosofia da educação; Pedagogo; Economista; professor do Programa de Pós-Graduação em Educação - PPGEdu-UCS; Pesquisador da Ação Educativa; Líder do grupo de pesquisa: juventude e práticas educativas em educação de jovens e adultos do CNPq.

E-mail: sergiohaddad@ucs.br

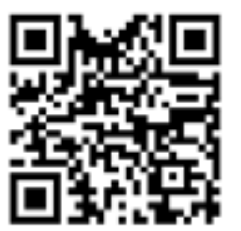

A autenticidade desse artigo pode ser conferida no site https://periodicos. set.edu.br

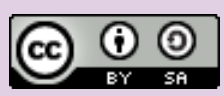

Este artigo é licenciado na modalidade acesso abertosob a Atribuição-Compartilhalgual CC BY-SA

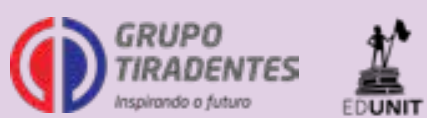

